\title{
Opera Jawa [Requiem from Java]: A Semiotic Narratology Perspective
}

\author{
Christian Budiman, Irwan Abdullah, and G. R. Lono Simatupang \\ Department of Media and Cultural Studies, Graduate School of Gadjah Mada University, Yogyakarta, INDONESIA \\ e-mail: kristologie@yahoo.com
}

\begin{abstract}
Directed by Garin Nugroho in 2006, Opera Jawa is an opera film with a special status in Indonesian film history, either perceived as a newly established genre or seen from many of its other aspects. Analyzed through a semiotic narratology perspective, this musical film can put forth deeper meanings than that of a mere triangle love story between the characters. The unveiling narrativity of every layer of Opera Jawa enables us to identify both its patterns of narrative syntagm and its actantial relations with its underlying system of values. This system consists of a set of antagonistically correlating main values, namely faithfulness versus deceit, and suppression versus power.
\end{abstract}

Keywords: Opera film, semiotic narratology, narrativity.

\section{INTRODUCTION}

Garin Nugroho is one of the most prominent figures in Indonesian film history. Among his films, Opera Jawa (2006) sets as the first opera film that he ever made, even until today, so to speak, the only genre during the course of Indonesian film history. Inspired by one of the most popular stories of classical literary treasure, the fragment of The Abduction of Sinta in Ramayana epic, this film recounts a lustful triangle love story between Setyo, Siti, and Ludiro which eventually leads them to a murderous brutal conflict. The married couple, Setyo and Siti, run a pottery business in a small village where Ludiro, a tremendously powerful butcher, lives. When the couple's business starts to decline, Ludiro avails himself of the situation. Ludiro, who has been harboring a long standing infatuation for Siti, tries to seduce and tempt her. Consequently, Setyo and Ludiro are entangled in an inevitable fight over Siti.

Besides the attention-grabbing genre, Sasono (2007) noticed the usage of other artistic media in this film. The installation art, for instance, can induce some implausible metaphors, diversity, and in-depth interpretation through the setting of the film, the dances can set as the element of acting expression, while the poetical tembang (Javanese songs) and the musical composition of karawitan are a courageous choice. Nonetheless, Sasono persistently considered the narrative elements as the strongest aspect of Opera Jawa.
On the basis of this opinion, we decided to thoroughly analyze the narrative aspect of Opera Jawa. This analysis is an attempt to use Greimas' $(1983,1987)$ model of close reading through two stages. The first was a close reading of the narrative aspect of Opera Jawa's two structural layers namely (1) the narrative syntagm and (2) the actantial relations constructing a narrative paradigm. Second, in order to complete the narrative structure analysis of the previous surface structure, an analysis was carried out into the deep structure, that is, the signification structure or ideological layer encompassing the value relations underlying the surface structure.

\section{SEMIOTIC NARRATOLOGY}

Semiotic narratology or narrative semiotics has become a classical field in the studies of text semiotics. The closest field of study to this is semiotics of literature, although basically narrative theories always deal with any text, even non-literary text, linking events structurally in the processes and time representative effects (Thwaites et al., 1994, pp. 111 \& 118; cf. Bal, 1988, p. 5). Narratology puts forward narrative analysis as the nature or special character of narrative text with an area of study unlimited by genre or certain media expression, embracing various trans-linguistic phenomena. In other words, these narrative texts can be discovered in any cultures of any languages (Nöth, 1990, p. 369; Greimas, 1987, p. 305). 
Narratology is basically influenced by or is in the traditional line with Russian formalism (i.e., Vladimir Propp) and French structuralism (i.e., Claude LéviStrauss). Propp (1928) with his book, Morphology of the Folktale (as cited in Nöth, 1990, pp. 367-368), is specifically considered as the early starting point of narratology. By his formalist approach, he could discover a structural narratology which is later known as the basic approach of narrative structure studies. Narrative syntax, the principals of narreme combination into a narrative structure, originated from Propp with his highly influential narrative theory, although later it is improved and revised over and over by subsequent narratologists such as LéviStrauss, Souriau, and Greimas.

Adapting the tradition pioneered by Propp, Greimas (1983, pp. 197-221; 1987, pp. 304-328; cf. Titscher et al., 2000, pp. 125-135), proposed a narrative semiotic approach derived from the basic assumption of the elementary structure of signification. This structure of signification is conceived of a set of binary oppositions dealing with the differentiation of two aspects from an entity, namely, opposite and contradiction: $\mathrm{A}$ is against $\mathrm{B}$ as $-\mathrm{A}$ and $-\mathrm{B}$.

\section{$A: B$ :: $-A$ : $-B$}

He considered these binary oppositions as the deep structure underlying an actantial model which in turn will generate the surface structure of every story. No story is free from the actantial structure if it is meant to be wholly meaningful.

Having made an inventory of all actants, Greimas then classified them into three sets of binary opposition bearing "the agent" of the story as described in the scheme below. Those actants will become the roles in their fictional action if they have social or cultural quality. In contrast, if they have individual quality, the actant will turn into acteurs or characters as traditionally termed in literary critics and general narratology.

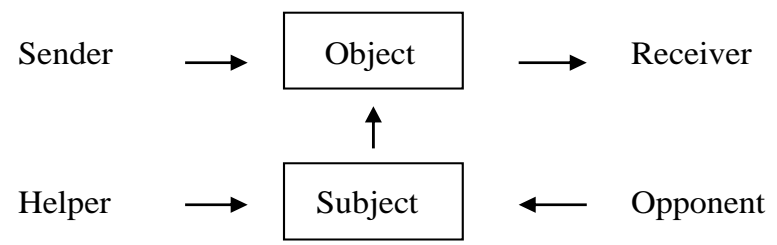

The above actantial model can be explained simply. It starts from a Subject wanting an Object, which is a thing communicated between the Sender and the Receiver. The Subject's want is assisted or supported by the Helper and is prevented by the Opponent. The relations in this actantial model were divided by
Greimas into three axes, namely (1) desire or quest; (2) communication; and (3) participation or contest. All those three axes are predicative axes which basically correlate one actant with another: Subject vs Object; Sender vs Receiver; and Helper vs Opponent.

When the inventory of those actants can be regarded as the arrangement of a narrative paradigm lexicon, we need to complete it with an additional inventory of the syntactic structures or structuration principals and a narrative grammar. On this account, Greimas differentiated three kinds of different syntagms. First is contractual syntagm (syntagmes contractuels), which leads the whole situation to bind or end a contract, alienation/separation, encounter or reintegration, and so forth. Second is performantial syntagm (syntagmes performanciels), which consists of sufferings, struggles, completing the task, and so forth. Third is disjunctional syntagm (syntagmes disjonctionnels), which consists of movements, adventures, departures, arrivals, and so forth.

The above Greimasian model will be used to analyze Opera Jawa through two steps. The first step is the inventory of its surface structure by reducing the narrative text into what we call its syntactic structure and actantial structure. The second step is the inventory of its deep structure by constructing the underlying main values which generate that surface structure.

\section{THE NARRATIVITY OF OPERA JAWA}

\section{Surface Structure}

Phase I. The narrative structure of Opera Jawa begins from the validation of an agreement, a contractual syntagm illustrated through a scene of Setyo and Siti holding animal's heart and taking a vow to stay faithful to each other as husband and wife before a religious specialist (Scene 1; 'Scene' hereinafter is referred to as $S c$.). The subsequent scenes project performantial syntagm indicating an equilibrium condition, a world of harmony for Setyo and Siti. Take, for instance, the scene when Siti does her hairbun, and when Setyo approaches her, caresses her, and makes out with her (Sc. 8). In this scene, Setyo sings a tembang (a Javanese song) analogizing his relationship with Siti to that of Rama and Sinta ("aku lan kowe kaya Rama lan Sinta"), who possess nothing but fidelity, prayer, and love ("sing isih pungkasan mung kasetyan, pandunga, lan katresnan"). However, this harmonious world of Setyo and Siti is not forever perfect. A scene (Sc.2) is directly presented to us right after the scene when Setyo and Siti are taking the faithful vow, becoming a 
foreshadowing of a crisis. In this scene, it is portrayed that Siti is afraid of a monster with a kukusan (a conic bamboo rice steamer basket) head chasing after and aiming at her groin, although eventually she can tame it by caressing its head. This creature seems to represent or at least is associated to Ludiro as what is clearly portrayed later in Sc. 43 when the kukusan serves as an iconic sign for Ludiro's phallic lust. Several other scenes also indicate the same point, for instance, the scene projecting several performantial syntagms describing Ludiro's men lining up, overspreading terror, murdering people at a market (Sc. 10), and hanging the victim's corpse (Sc. 11). In brief, the first phase of the narrative structure of Opera Jawa is elaborated within a contractual syntagm and a set of performantial syntagms in order to present equilibrium (see Gripsrud, 2002, p. 193), a harmonious world of Setyo and Siti, and yet, to forecast seeds of crisis due to the elements of fear and violence brought by Ludiro.

Phase II. This phase is begun by the scene of Setyo ordering and assigning Sura to look after Siti while he is away to sell pottery (Sc. 13). "Kawajibanmu tunggu omah, jaga bojoku [Your task is to take care of my house and look after my wife]," says Setyo while handing over the house key to Sura. Here, we can see an intertwined contractual syntagm between Setyo and Sura which is followed by a set of performantial syntagms in the following scenes. Among the scenes, tucked a special performantial syntagm, that is, a scene about Sukesi, Ludiro's mother, who asks him to make a red scarf to win Siti's heart (Sc. 15). This scene is special because it leads the plot to the next contractual syntagm elaborated in the three events as following. First, Ludiro invites Siti, through a letter sent by a courier, to dance at his house (Sc. 16). Second, when Setyo is baking pottery in the house yard and Siti is cooking rice in the kitchen, Ludiro and his men suddenly appear in the kitchen and he seduces her (Sc. 19) - it is obvious that in this scene Siti positively responds to Ludiro's seduction. Third, consequently Ludiro gets the shot to make out with Siti, while Setyo rejects making out with her (Sc. 20). All those three scenes are none other than the projection of two contractual syntagms opposing each other namely (1) the beginning of a relationship agreement between Ludiro and Siti, and (2) the end of the faithful bond between Siti and Setyo. In other words, this narrative part presents the first phase of the downfall of equilibrium or the start of a complication, or a critical situation, through a set of performantial syntagms enclosed by some contractual syntagms.

Phase III. Again, a contractual syntagm starts and ends the next phase. It starts from the scene of Setyo refusing Siti, who wants to accompany his departure to sell pottery at the market (Sc. 21). This event is none other than the set of Setyo's conduct centralizing on contractual syntagm. Upon returning from the market, he finds an empty house (Sc. 24) which leads him to question Siti's love and faithfulness. "Apa isih ana katresnan, apa isih ana kasetyan ing atine garwaku? [Is there still any love, is there still any faithfulness inside my wife's heart?]" asks him. Triggered by rage, he immediately commands Anom to search for Siti. The set of scenes elaborated in performantial syntagms is ended by two parallel events indicating a conflict due to a broken contractual bond. Those two events are exactly situated in the last scene constituting of a chronological events when Setyo's troupe are lining up and Ludiro's troupe are getting ready for battle (Sc. 30-31). Thus, the conflict between Setyo and Ludiro is at stake.

Phase IV. The next phase is signposted by the battle scene illustrating the defeat of Setyo before Ludiro, and the hung corpses all along the village street are cremated by some women (Sc. 33-34). Ludiro and Siti then appear in the following two scenes. First, Ludiro smokes at a stall and dances on a table accompanied by Pewarta (storyteller), who narrates Ludiro's lust through a song (Sc. 35): "maniku muncrat neng langit [my sperm spurts to the sky]" - a line analogizing Ludiro's unbearable lust for Siti. Second, Siti combs a twisted hair and tidies up several hair buns at her house (Sc. 36). These two scenes, as just like other previous and subsequent scenes, are only illustrated through performantial syntagm. Other scenes also explicitly indicate Setyo's defeat (Sc. 37, Sc. 38). Even there are two scenes ending this phase through a contrast. On one side, Ludiro dances a victorious celebration at the slaughterhouse (Sc. 39) and, on the other side, Setyo tremblingly dances in grief and defeat (Sc. 40).

Phase V. Ludiro comes home when Sukesi is teaching the children dancing at the house yard. Upon seeing his arrival, Sukesi once again asks Ludiro to find a woman to be his spouse. Ludiro then replies by expressing his captivation to one woman only, Siti. In this scene (Sc. 41), Ludiro and his mother come to an agreement to win Siti's heart. The contractual syntagm is then followed by performantial syntagm in the scene depicting Sukesi assisting Ludiro by sewing a sheet of red cloth which will become a red carpet for welcoming Siti to come into Ludiro's embrace (Sc. 42). The cloth is outstretched and extended to Siti's house. She then traces all along the cloth and arrives at Ludiro's house. Upon her expected arrival, Ludiro welcomes her by 'caressing' her face with his foot palm and whipping her by a sheet of cloth. Beyond all 
questions, Siti refuses this brusqueness (sexual harassment) and tries to strive against him. Siti successfully manages to escape while Ludiro stands still in his own red cloth bind (Sc. 45). This last scene shows a set of actions intertwined in a contractual syntagm, that is, the breaking up of Ludiro and Siti due to harsh conduct of sexual relation committed by Ludiro. Thus, all set of scenes in this phase lead to the further complication from the previous phase which is dealing with the critical situation in the triangle love story between Setyo, Siti, and Ludiro. This phase is mainly illustrated through a set of performantial syntagms enclosed by two contractual syntagms.

Phase VI. When Siti returns to her house, Setyo acts indifferently due to his jealousy and anger (Sc. 46). Once again, the syntagm in this scene portrays the broken contractual bond between them. The following scenes project a set of performantial syntagms leading to the outbreak of a big battle. It starts from the raged and jealous Setyo, who orates in front of his followers (Sc. 48), and continues to Anom, who lines up with his troupe to get ready for the battle (Sc. 49-50). Knowing this, Ludiro becomes irritated $(S c$. 51). He and his troupe start to get ready, too. They march and sharpen their parang knives preparing for the battle (Sc. 53). All those events above emerge due to a culminating conflict between Setyo and Ludiro in fighting over Siti's love. The two parallel scenes illustrating performantial syntagms, that is, Ludiro and Setyo each preparing their troupe (Sc. 55-56) and a contractual syntagm scene of the outbreak battle ( $S c .57)$ end this phase. Thus, it seems that this phase repeats the pattern of the previous phase when the first conflict between Setyo and Ludiro occurs for the first time. The pattern is projected as a set of performantial syntagms enclosed by two contractual syntagms.

Phase VII. The climax of Opera Jawa narrative structure lies in the scene leading to the death of Ludiro. This incident is illustrated through a set of long performantial syntagms ended by Ludiro's ripped body (Sc. 59) causing his death (Sc. 60). The death of Ludiro, which means a peripeteia or a turning point (see Gripsurd, 2002, p. 193) of Setyo's victory, is the culmination of the crisis and conflict which has been going on so far between them for winning Siti.

Phase VIII. The war is over. Siti goes to the beach (Sc. 63) and not long after, Setyo follows her (Sc. 65). With a perplexed face, Setyo pulls out Siti's hair pin. Then, while embracing and kissing her, he pricks Siti's body with her hair pin. She dies in her husband's hand. Afterwards, Setyo rips her chest and pulls out her heart (Sc. 66). All these events are mainly projecting disjunctional syntagms combined with a performantial syntagm, which are shown in the scene of Setyo killing Siti. The next disjunctional syntagm lies in Suksesi's scene dressing in black cloth and black veil as the symbol of condolence, going out of her house (Sc. 69) together with Sura and a long line of people marching slowly along the beach by carrying sesaji (offerings to gods/goddesses), gunungan (a representation of Mount Meru whose function during Javanese shadow puppets performance is to mark the beginning of each scene), rice pots, corpses, and slashes of human flesh and heads (Sc. 70). This phase ends with a brief scene of a bush of rice plant growing inside a ragged and burned cloth tent (Sc. 72). This structural narrative phase of Opera Jawa is dominated by disjunctional syntagm and it sets as the end of the whole story, letting the world evolves in disequilibrium. Here, we can see hardly any world recovery, but the illustration of the bush of rice in the last scene probably signposts the coming of new equilibrium.

The summary of the whole narrative syntagm can be seen in the following table.

Table 1. The narrative syntagm

\begin{tabular}{ll}
\hline Phase & Narrative Syntagm \\
\hline I & $\mathrm{C} \rightarrow \mathrm{P}$ \\
II & $\mathrm{C} \rightarrow \mathrm{P} \rightarrow \mathrm{C}$ \\
III & $\mathrm{C} \rightarrow \mathrm{P} \rightarrow \mathrm{C}$ \\
IV & $\mathrm{P} \rightarrow \mathrm{P}$ \\
V & $\mathrm{C} \rightarrow \mathrm{P} \rightarrow \mathrm{C}$ \\
VI & $\mathrm{C} \rightarrow \mathrm{P} \rightarrow \mathrm{C}$ \\
VII & $\mathrm{P} \rightarrow \mathrm{P}$ \\
VIII & $\mathrm{D} \rightarrow \mathrm{P}$ \\
\hline
\end{tabular}

Explanation:

C Contractual Syntagm

P Performantial Syntagm

D Disjunctional Syntagm

$\rightarrow$ Syntagm Shift

The above narrative description is not yet finished because it only lies at the narrative syntagm dimension. Therefore, we need to complete it with the so-called narrative paradigm by investigating the relations between its lexicons referred to as actants. On the basis of the investigation, we can see that the narrativity of Opera Jawa basically only begins in the second phase or part (Sc. 13-20) which continues to the third phase (Sc. 21-31), fourth phase (Sc. 32-40), and fifth phase (Sc. 41-45), that is when Ludiro appears with his narrative action of desiring something (actually someone), namely Siti, to be his spouse. Here, we can see that Ludiro plays the role as the Subject, while Siti serves as the Object (Sc. 15, 19, $20,23,35,41$, and 45). Indeed, throughout the film, 
there is no explicit information regarding who or what sends Siti, yet it is clear that the Receiver part, if the attempt is successful, is Ludiro himself. Then, the other actants clearly take the position of the Helper and Opponent for Ludiro's attempt. Sukesi, the courier, the letter, the candles, the troupe, and Ludiro's men are the Helper (Sc. 15, 16, 23, 31, 41, 42, and 31), while Setyo, Sura, Anom and his troupe are the Opponent (Sc. 13, 17, 20, 23, 24, 25, 30, and 42). In brief, if we elaborate the predications, Ludiro's desiring to get Siti correlates with the other two narrative actions, namely helping as well as preventing what is done by other actants. The actantial relations of the above explanation are illustrated by the following scheme (Figure 1).

Several shifts and role inversions occur since the sixth phase (Sc. 46-57), and continue until the seventh phase (Sc. 58-62) and eighth (Sc. 63-71), when Setyo wants to win Siti back over Ludiro. In other words, since involving in this phase, Setyo plays the role as the Subject desiring Siti as an Object (Sc. 47, 48, 56, 65 , and 66). Just like in the previous phase, the Sender position is also unknown in this text, yet the Receiver actant (if the Subject's attempt is successful) this time is occupied by Setyo himself. Due to the shift, the role of Helper and Opponent are also inverted. Sura, Anom with his troupe in this part serve as the Helper (Sc. 13, 17, 49, 50, 56); meanwhile it is obvious that Ludiro and his troupe, also Sukesi and the red cloth, serve as the Opponent (Sc. 42, 53, and 55) for Setyo's attempt to get the Object.

The shift in the last actantial relations is described in Figure 2.

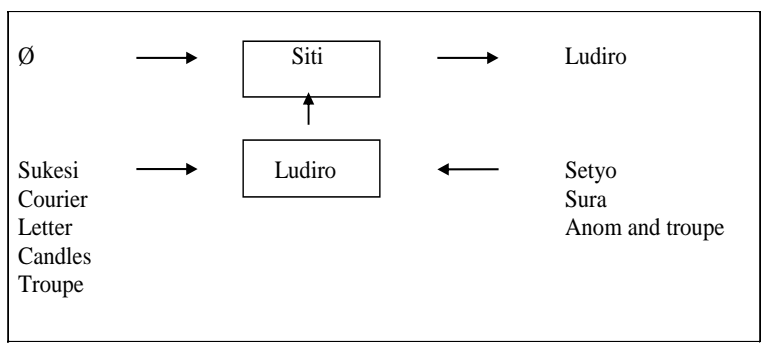

Figure 1. The actantial relations

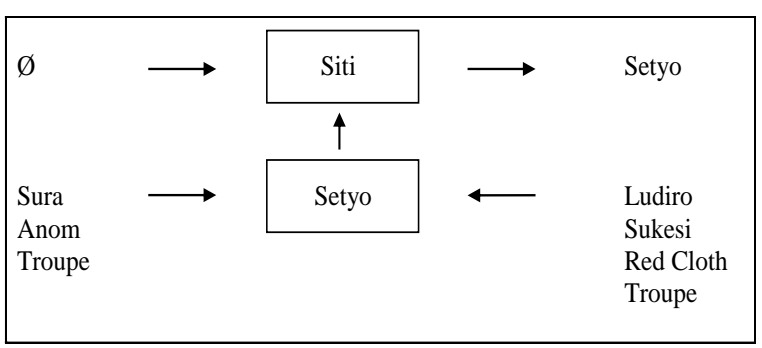

Figure 2. The shift in the last actantial relations

\section{Deep Structure}

Having analyzed the surface structure of Opera Jawa consisting of a chain of narrative syntagms and paradigms (actantial relations), we can thus identify several certain classems or semantic terms (semes) which appear several times in the text (Culler, 1982, p. 79). These terms, besides serving to maintain the coherence of the text, serve as the underlying values (Titscher et al., 2000, p. 128) striven by the actants and are contradicted in the relations between the main actants in it. The first term of value is faithfulness, which is personified through Setyo's actant (Sc. 1, 65, so forth). In contrast, Siti represents deviation, deceit, or betrayal (Sc. 19, 20, 23, 42, and so forth). The next term is power or dominance, which is personified by Ludiro's actant (Sc. 09, 10, 39, and so forth). The last term brings a contradictory value to the values brought by Setyo-Siti. Both Setyo and Siti, in contrast to Ludiro, obviously represent weakness, inability, even we may call it suppression (Sc. 17, 38, 40, 47, and so forth). The conflicts taking place between them are mainly triggered by these contradicted values, that is between faithfulness and betrayal; dominance and suppression (both of which, in the most extreme case, can potentially turn into violence). In brief, if Setyo mainly represents faithfulness value, Siti represents betrayal; if Setyo-Siti represents suppression, then Ludiro represents dominance.

The relations constructing the deep structure of Opera Jawa as a narrative text can be described in the following semiotic square (Figure 3).

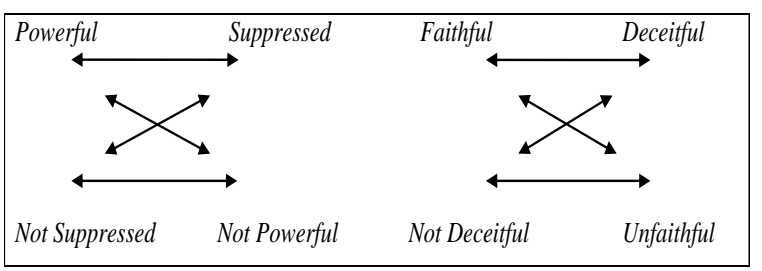

Figure 3. The deep structure

Or, if illustrated as four-term homology, it will be the following:

Powerful : Suppressed :: Not Powerful : Not Suppressed Faithful : Deceifful :: Unfaithful : Not Deceitful

\section{CONCLUSION}

Analyzed from semiotic narratology perspective, particularly Greimas structural approach, Opera Jawa can be classified into the layer of surface structure and deep structure. The former consists of a narrative syntagm which is mainly constituted of intertwining contractual and performantial syntagms elaborating the harmonious tiny world of Setyo and Siti, an equilibrium which gradually leads into a crisis, a disequilibrium. The presence of betrayed or broken 
contractual syntagm leads to a conflict between Setyo and Ludiro in winning over Siti's love and attention. Such a pattern of relationship is repeated over and over so that it is completed by disjunctional syntagm to let the world be in its disequilibrium condition. Still in this layer, regarding the narrative paradigm, several shifts and inversions of actants' roles occur, particularly for the Subject position (Ludiro's position is substituted by Setyo), which consequently changes other actants' roles, except Siti, who stays at her position as the Object. The latter layer, referred to as the deep structure, is an ideological signification structure underlying Opera Jawa's narrativity. This structure consists of a set of antagonistically correlating main values, namely faithfulness versus deceit and suppression versus power. It can be said that Opera Jawa as a narrative text provides an interesting opportunity for interpretation. This film is not merely a story of romantic love triangle, but also offers a reflection on the more fundamental dimension of values which is linked to the relations of power even the problem of oppression among human beings.

\section{REFERENCES}

Bal, M. (1988). Narratology: Introduction to the theory of narrative. Toronto: University of Toronto Press.
Culler, J. (1982). The Structuralist poetics: Structuralism, linguistics, and the study of literature. Ithaca, NY: Cornell University Press.

Greimas, A. J. (1983). Structural Semantics: An attempt at a method. Lincoln: University of Nebraska Press.

Greimas, A. J. (1987). Elements of a narrative grammar. In V. Lambropoulos \& D. N. Miller (Eds.), Twentieth century literary theory (pp. 304-328). Albany, NY: State University of New York Press.

Gripsrud, J. (2002). Understanding media culture. London: Arnold.

Nöth, W. (1990). Handbook of Semiotics. Bloomington \& Indianapolis: Indiana University Press.

Sasono, E. (2007, February 2). Medium dan bentuk hibrida Opera Jawa [Medium and hybrid of Opera Jawa]. Kompas. Retrieved from http://ericsasono.multiply.com/reviews/item/32

Sellars, P. (Producer) \& Nugroho, G. (Director). (2006). Opera Jawa [Javanese Opera] [Motion Picture]. Indonesia: SET Film Production.

Thwaites, T., Davis, L. \& Mules, W. (1994). Tools for Cultural Studies: An introduction. South Melbourne: Macmillan.

Titscher, S., Meyer, M., Wodak, R., \& Vetter, E. (2000). Methods of text and discourse analysis. London: SAGE Publications. 